\title{
A Simplified Prediction Method of Real Fire Exposure as a Basis for an Analytical Structural Fire Design
}

\author{
VLADIMIR M. ROITMAN, VLADIMIR N. DEMEKHIN and \\ MOHAMMED A. ABDUL MAJEED \\ Moscow Civil Engineering Institute \\ Yaroslavskoye Chaussee 26, Moscow 129, USSR
}

ABSTRACT

This paper presents a method for predicting the fire temperature -time curve in compartments as a part of a analytical approach for the determination of fire behaviour and loadbearing capacities of structures and structural elements. Existing data in the basis of greph were analysed and equations derived on the basis of results of analysis are eugeested for the calculation of the temperature-time curve in compartments.

KEYWORDS: fire behaviour, real fire, temperature-time curves. fire load, opening factor.

INTRODUCTION

A fully analytical evalution procedure of fire behaviour of structural elements and structures with the consideration of real fire exposure can be subdivided into three main steps: prediction of; compartment fire temperature-time cur$v e$, temperature-time fields in the structure and the reduction rate in load-carrying capicity of the structure until reaching a limit state condition.

If the prediction of fire resistance for elements is made on the basis of the standerd temperature-time curve, then the first step (prediction of compartment fire temperaturetime curve) is deleted, since using the standard temperaturetime curve is a treditional practice in solving fire resistance design problems.

Cbservations of and research on the consequences of rea. fires in different objects show [1-5], that their gas temperature-time curves can be very different from the standard curve. This necessitates such supplements to the evalution procedure of fire behaviour of structural elemente and etructures, that permit the consideration of the whole "thermel" history of fire development in compartments.

\section{DEVELOPNENI AND MAIN CHARACTERISTICS OF FIRE BEHAVIOUR}

According to the fire engineering design approach euggested in references $[9,10]$ the real fire exposure, depends 
upon three main parameters:

$\Psi$ - coefficient of fire intencity, which expresses the ratio of gastemperature in compartment in any moment of fire exposure to the temperature of the standard fire at the some time;

$\tau_{m}$ - the time to reach the maximum gastemperature in compartment $t_{m}$, min in a real fire exposure;

$V_{0}$ - a parameter, which characterizes the descending rate of gastemperature in compartment in the stage of fire decay, ${ }^{\circ} \mathrm{C} / \mathrm{min}$.

The existing data on fire exposure models in compartments [2, 3, 4] are given in a system of tables and nomograms. In this form, these data are used with some difficulty for calculation purposes.

The aim of this contribution is to get a system of equations for the determination of the real fire parameters, which permits their direct use in calculations of the structural fire behaviour.

To achieve this eim, it became necessery to evalute how the parameters $\psi, \tau_{m}$ and $V_{c}$ depend upon the fire load in compartments, the conditione of ventilation and other factors.

As widely acknow]edged [2-5], the main factore, which determine the fire tempereture-time curve in compertments, are the fire loed density a $\left(\mathrm{MJ} / \mathrm{m}^{2}\right)$, the conditions of ventilation and the thermal properties of the structures enclosing the compartment. These influences are expressed by the following factors:

$K_{1}=\frac{A_{2} \sqrt{H}}{A_{3}}$

$K_{2}=\frac{A_{1} \sqrt{H_{1}}}{A_{2} \sqrt{H}}$

$K_{1, \text { red }}=f_{1} \cdot f_{2} \cdot K_{1}$

$q_{r e d}=f_{1} \cdot q$

where

$K_{1}$ and $K_{2}$ - opening factore for vertical and horizontal openings, respectively, $\mathrm{m}^{1 / 2}$;

$A_{1}$ and $A_{2}$ - area of vertical and horizontal opening of the compartment, respectively, $\mathrm{m}^{2}$; 
$A_{3}$ - total boundery surface area of the compartment, openings areas included, $\mathrm{m}^{2}$;

H - average height of verticel opening of the compartment,m;

$H_{1}$ - the distance from the plane of horizontal opening to the centre of the vertical openings, m;

$\mathrm{K}_{1}$, red - equivalent opening factor, $\mathrm{m}^{4} / 2$;

ared - equivalent fire load deneity, $11 \mathrm{~J} / \mathrm{m}^{2}$.

The value of coefficients $f_{1}$ and $f_{p}$ are determined by using tabele 1 and 2 respectively $[3,4]^{2}$.

TABLE 1

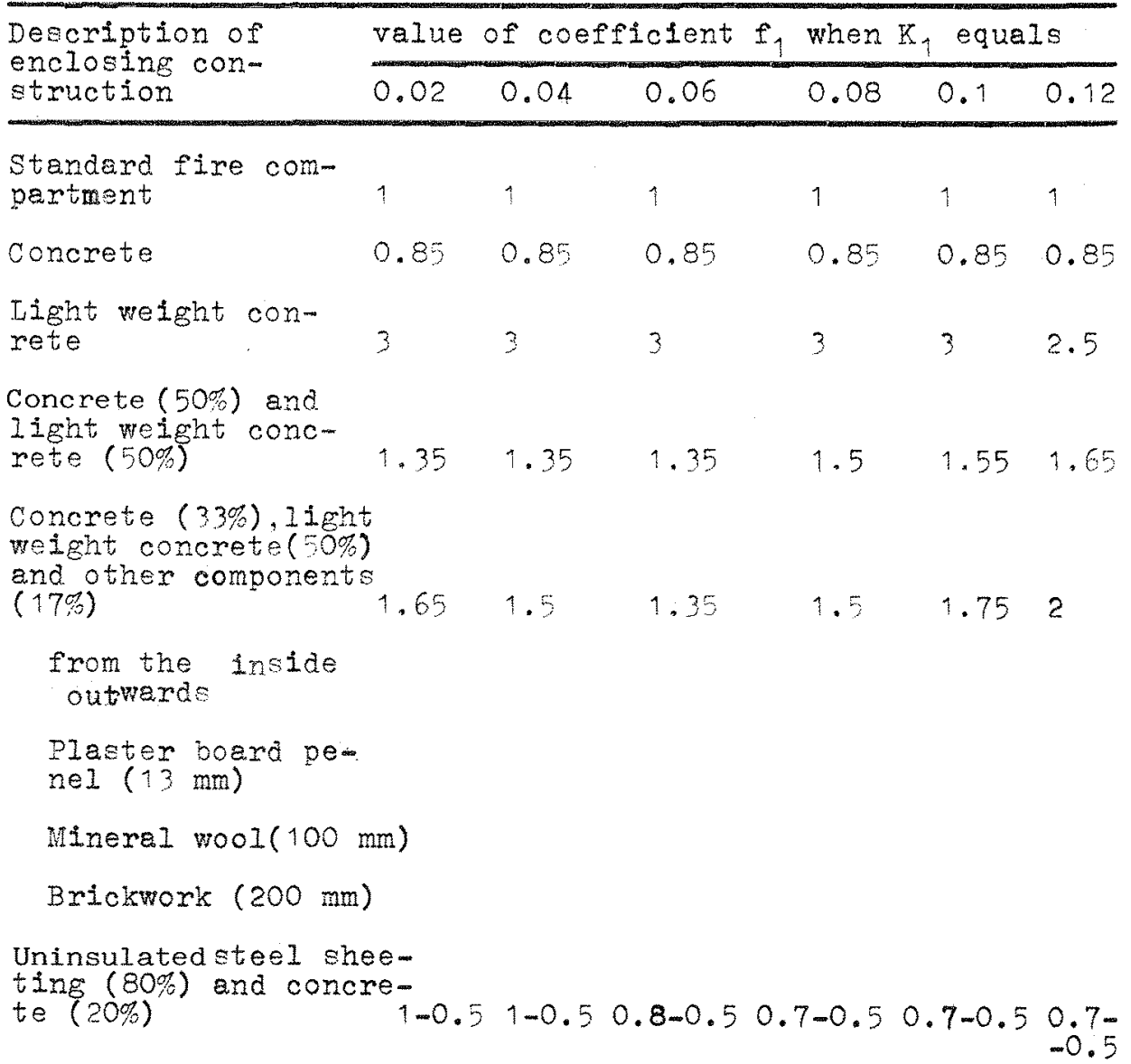




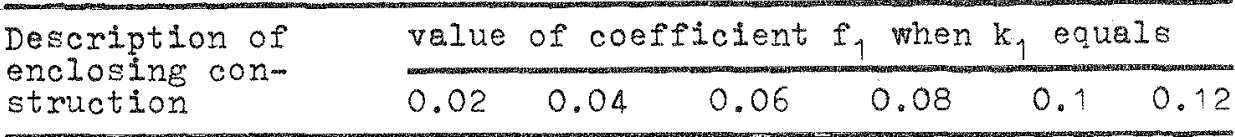

Concrete $(20 \%)$, two

plasterboad panels

$(2 \times 13 \mathrm{~mm})$

$\begin{array}{llllll}1.5 & 1.45 & 1.35 & 1.25 & 1.15 & 1.05\end{array}$

Sheet steel - dia-

base wool ( $100 \mathrm{~mm}$ )

- sheet steel

3

3

$3 \quad 3$

$3 \quad 2.5$

TABLE 2

\begin{tabular}{cccc}
$K_{2}$ & $f_{2}$ & $K_{2}$ & $f_{2}$ \\
\hline 0 & 1 & 1 & 3.2 \\
0.5 & 2.1 & 1.5 & 4.6 \\
\hline
\end{tabular}

\section{ANALYSIS AND RESUTTS}

In order to establish a relation between parameters $\psi$, $\tau_{m}, V_{c}$ and the values gred and $K_{1}$,red, the graphs of fire temperature-time curves (Fig. 1) $[2,3,4]$, which were derived by solving the energy and mase balance equations of the compartment fire and verified by experimental results, were carefully analysed. The results of the analysis showed that:

- the coefficient of fire intensity $\Psi$ does not deper end upon the fire load density axed, but is influenced by the opening factor $K_{1, \text { red }}(\mathrm{R} i \mathrm{~g} .2)$;

- the time to reach the maximum value of gaetemperature in compartment $\tau_{m}$ is directly proportionel to the fire 10. ad density and inversely proportionel to the opening factor ( $\operatorname{Lig} 3)$;

- when the fire load density increases, the value of parameter $V_{C}$ decreases (Fig. 4).

After the mathematical approximation of the reaults of analysis (Fig. 2-4), the following equations are euggested for $\psi$, $\tau_{m}$ and $V_{C}$ ( $K_{1, r e d}$ in $\mathrm{m}^{1 / 2}$ and $q$ red in $\left.\mathrm{MJ} / \mathrm{m}^{2}\right)$ :

$\Psi=1.37-\frac{150 \mathrm{~K}_{1}, \text { red }}{-0.65} \frac{-0.000}{\left(\mathrm{~K}_{1}, \text { red }\right)^{2} \times 10000}$ 


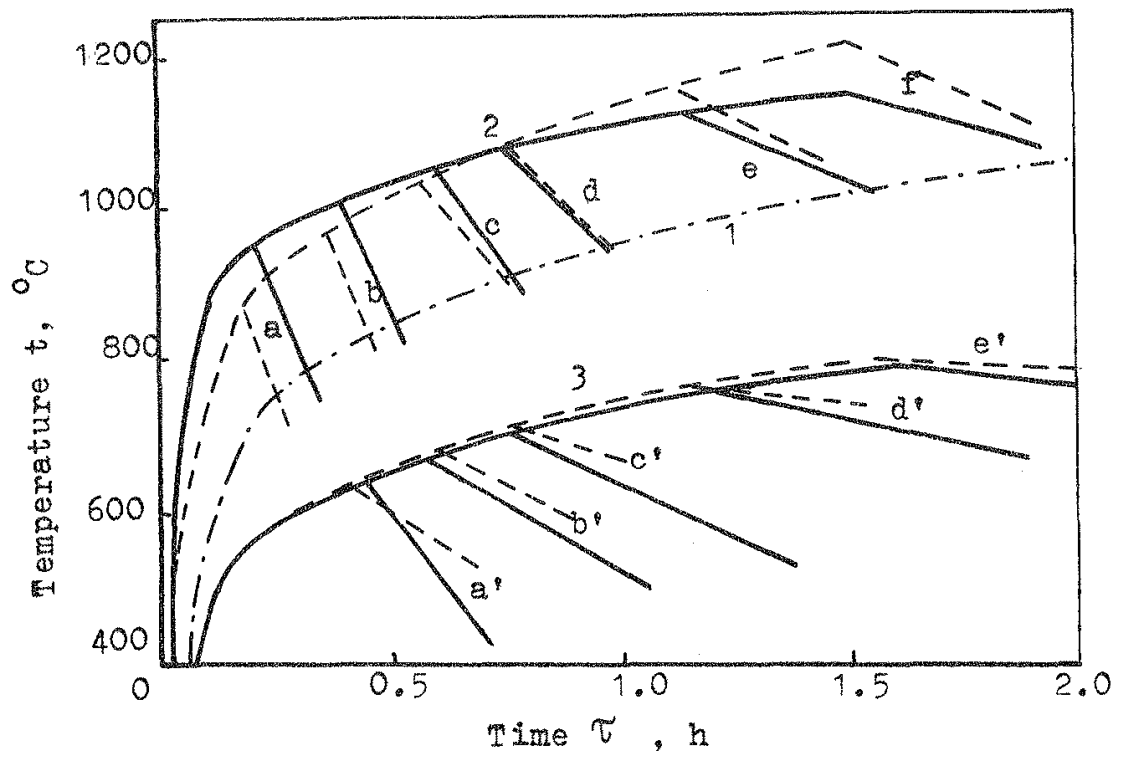

FIGURE 1. Fire gestemperature-time curves in compartment for different values of factor of opening $\mathrm{K}_{1}$ red $\left(\mathrm{m}^{1 / 2}\right)$ and fire load ared $\left(\mathrm{MJ} / \mathrm{m}^{2}\right)$ :

1. The ctanderd tempereture-time curve. 2. Fire temperaturetime curves for $\mathrm{K}_{1, \mathrm{red}}=0.08$ and $a-q_{\text {red }}=151, b-251$, c $-377, d-502, e-754, f-1004,3$. Fire temperature-time curves for $X_{1, \mathrm{red}}=0.02$ end: $a^{\prime}-\mathrm{q}_{\mathrm{red}}=62.8, b^{1}-94,2$, $c^{\prime}-126, d i=188, e^{i}-251$. data of ref. [2], $\ldots \ldots$ calculation reaults by The suggested method.

U

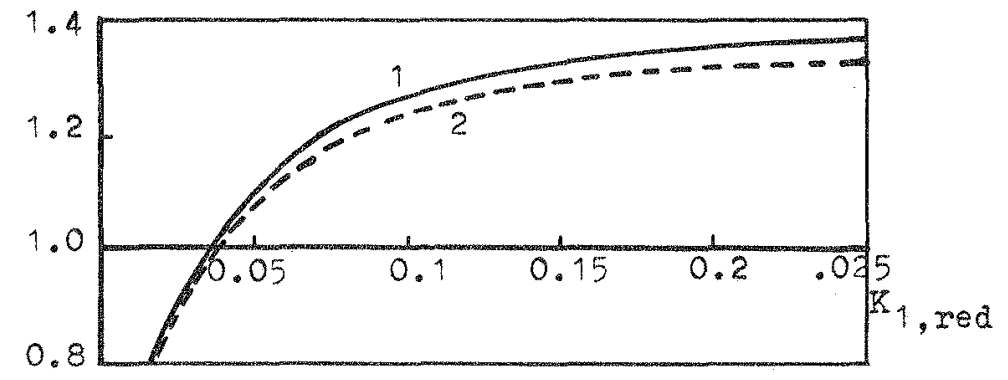

FIGURE 2. Relationship between coefficient of fire intensity and factor of opening $\mathrm{K}_{1, \mathrm{red}}(\mathrm{m} / \mathrm{2})$ :

1. data of ref. [2];

2. calculation xesults by using equation (5). 


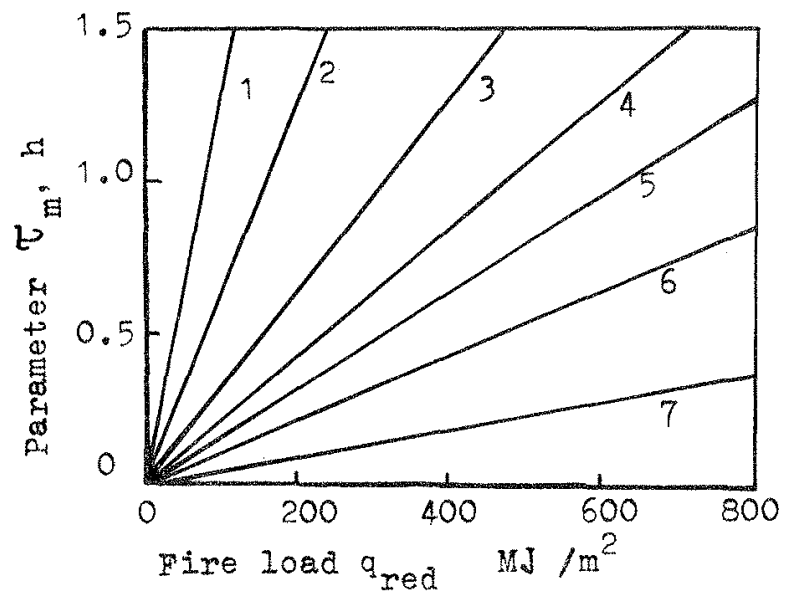

FIGURE 3. Relationship between time $\tau_{m}$ of reaching the maximum gastemperature in compartment fire and fire losd ared for different values of factor of opening $\mathrm{K}_{1, \mathrm{red}}(\mathrm{m} / 2)$ analysis of data of ref [2].

$1-K_{1 \text { reat }}=0.01,2-0.02,3-0.04,4-0.08,5-0.12,6-0.03$

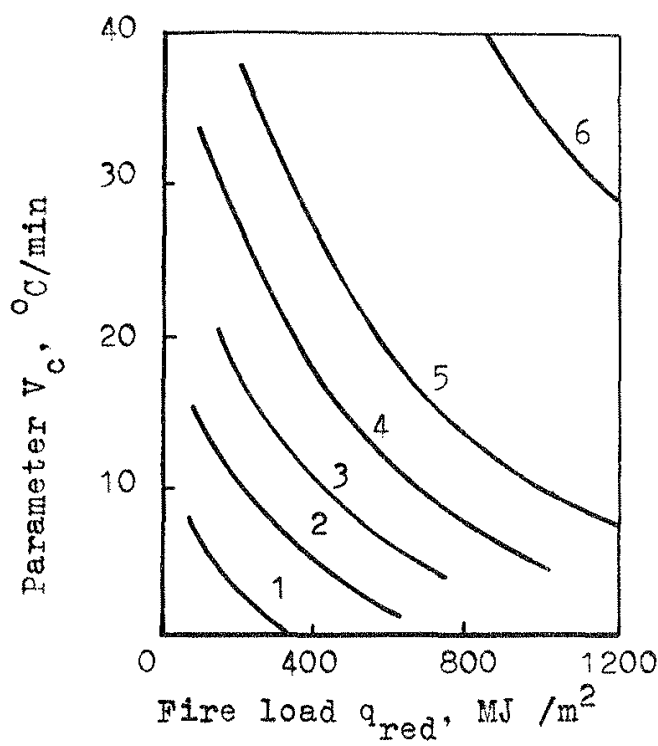

FIGURE 4. Relationship between the descending velocity $V_{c}$ of fire gastemperature in compartment in the stage of fire decay and fire load a red for different values factors of openings $K_{1}$ red $(\mathrm{m} / 2)$ - analysis of data of ref [2]:

$1-K_{1, r e d}=0.02,2-0.04,3-0.06,4-0.08,5-0.12$, $6-0.3$. 


$$
\begin{aligned}
& \tau_{m}=\frac{60 q_{\text {red }}}{8318 \mathrm{~K}_{1, \text { red }}-4021\left(\mathrm{~K}_{1, \text { red }}\right)^{2}} \\
& \nabla_{c}=\frac{98000 \mathrm{~K}_{1, \text { red }}-1500}{q_{\text {red }}}
\end{aligned}
$$

The value of gastemperature $t$ in compartment at time

$\tau_{i}$ (min) of fire exposure can be determined by the following equations:

when $\tau_{i}<\tau_{m}, t_{f}(\tau)=\psi \cdot 345 \log \left(8 \tau_{i}+1\right)+t_{0}$

when $\tau_{i}>\tau_{m}, t_{f}(\tau)=\psi \cdot 345 \log \left(8 \tau_{i}+1\right)-$

$$
-v_{c}\left(\tau_{i}-\tau_{m}\right)+t_{0}
$$

where

$t_{0}$ - temperature of compartment at $\tau_{i}=0,{ }^{\circ} \mathrm{C}$.

\section{DISCUSSION}

The calculation results of fire temperature-time curves by using formules (1-9), are shown by dashed lines in Fig. 1 , compared with data in ref.[2]. The comparison shows that equations $(1-9)$ are sufficientiy accurate for practical purposes.

Example: given - dimensions of compartment: $11.8 \times 6.05 \times$ $3 \mathrm{~m}$ area of vertical openings; $A=0.9 \times 2+2(1.5 \times 1.5)=$ $6.3 \mathrm{~m}^{2}$; average height of vertical openings: $\mathrm{H}=1.615 \mathrm{~m}$; fire load density: $q=272 \mathrm{MJ} / \mathrm{m}^{2}$; material of bounding etructures: normal concrete.

Determine the values of the parameters of real fire. SoIution -1 . area of bounding stxuctures $A_{3}=2(11.8 \times 6.05+$ $6.05 \times 3+11.8 \times 3)=249,88 \mathrm{~m}$.

2. determine the opening factor $K_{1}$ by equation (1):

$K_{\uparrow}=\frac{6.3-\sqrt{1.615}}{249.88}=0.032 \mathrm{~m} / 2$

3. by using table 11 coefficient $f_{1}=0.85$

5. determine the equivolent opening fector by equation (3):

$K_{1, \text { red }}=0.85 \times 0.032=0.0272 \mathrm{~m} / 2$

6. determine the equivalent fire load deneity by equation(4): $q_{\text {red }}=0.85 \times 272=231 \mathrm{MJ} / \mathrm{m}^{2}$ 
7. determine parmeter $\Psi, \tau_{\mathrm{m}}$ and $\nabla_{\mathrm{c}}$ by equations $(5-7)$ :

$$
\begin{aligned}
& \Psi=1.37-\frac{150 \times 0.0272-0.65}{(0.0272)^{2} \times 10000}=0.907 \\
& \tau_{m}=\frac{60 \times 231}{8318 \times 0.0272-4012 \times(0.0272)^{2}}=62 \mathrm{~min} \\
& V_{c}=\frac{98000 \times 0.0272-1500}{231}=5.05{ }^{\circ} \mathrm{c} / \mathrm{min}
\end{aligned}
$$

\section{CONCLUSIONS}

Together with the method given in references $[9,10]$ equations (1-9) enable an efficient prediction of flre behaviour and load bearing capicity of structural elements to be carried out with the consideration of real fire exposure (and not only standard fire). The method can aloo used for research purposes and an estimation of the structural sefety of buildinge after fires and other engineering probleme.

\section{REFERENCES}

1. Lie, T.T., Characterietic Tempereture Curvec for Varlous Fire Severities, Fire Technology, 10:4, 315-726, 1974.

2. Magnussen, S.E., Thelanderson, S. "Temperature-Time Curces for the Complete Process of fire Development. A Theoritical Study of Wood Fuel Fires in Enclosed Spaces", Acta Polytechnica Scandinavica, Ci 65, Stockholm, 1970.

3. Pettersson, 0., Magnusson, S.E., Thor, J., Fire Engineering Design of Steel Construction, Stockholmm 1976 (Swedish end., 1974).

4. Berthelemy, B., Kruppa, J., Resistance en Feu des Structu res Beton-Acier-Bois, Edition Eyrolies, Paris, 1978.

5. Harmathy, T.Z., Nchaffey, J.R., Post-Flashover Compartment Fires, Fire and Material, $7: 2,198 ?$.

6. Kordine, K., Aktuelle Problems des vorbeugenden baulichen Brandschuts, Betonwerk, Fert1gteil, Tech., 48:8, 509-517, 1982.

7. Wickstorm, U., Applacation of the Standard Fire Curve for Exprecsing Natural Fires for Design purposes, Fire Safety Sclence and Engineering, ASTM STP 882, Phyladelphia, 145$159,1985$.

8. Petterseon, 0., Practical Need of Scientific Material Modele for Structural Fire Design - General Review, Fire Safety Journal, $13: 1,1-8,1988$. 
9. Roitman, V.M. With Account of the Real Fire Impect, Pozharnce delo (Fire Engineering), 3, 19-20, 1988.

10, Roitman, V.M., Yesterday Stereotypes or New Approech? On the Theory of the Structural Fire Resistanc Analysis, Pozamoe delo (Fire Engineering), 9, 8-10, 1989. 
